\title{
DERECHO AMBIENTAL EN LA CONSTITUCION PERUANA
}

Guillermo Figallo

$\mathrm{El}$ artículo $123^{\circ}$ establece que: "todos tenemos el derecho de habitar en un ambiente saludable, ecológicamente equilibrado y adecuado para el desarrollo de la vida y la preservación del paisaje y la naturaleza. Todos tenemos el deber de conservar dicho ambiente". ambiental".

"Es deber del Estado preservar y controlar la contaminación

De este modo nuestra Carta Fundamental, como la mayor parte de las Constituciones posteriores a la Segunda Guerra Mundial, reconoce la existencia del ambiente como un nuevo bien jurídico integral que debe ser conservado.

\section{CONCEPTO DE AMBIENTE}

Según A. Pérez Luño, la expresión "ambiente" tiene un sentido multivoco. Así se habla de ambiente físico, o natural, integrado por la biósfera, que equivale al conjunto de recursos naturales (elementos y procesos) y los ecosistemas producto de la interacción de los seres vivos y el medio. También se considera el ambiente cultural formado por los espacios cerrados, construidos por el hombre, las manufacturas o productos si son físicos y las instituciones si son inmateriales; por último integra el ambiente el resto de la humanidad. Por otro lado se ha llegado a identificar hasta cinco modalidades de ambiente:

a) El climático o metereológico;

b) El físico o los recursos que el hombre organiza para satisfacer sus necesidades;

c) Los asentamientos que configuran cierto habitat; 
d) Las formas sociales de trabajo o recreación; y

e) Los factores que promuevan o comprometan la salud.

Existe una concepción amplia del ambiente como "el conjunto de factores físicos, sociales, culturales, económicos y estéticos que afectan al individuo y a las comunidades, que determinan su forma, carácter, relación y supervivencia natural. (National Environment Policy Act.).

Otros lo definen simplemente como "el entorno natural". En otras palabras, el ambiente es un concepto genérico que comprende todos los factores y fuerzas externas a los que responde efectiva o potencialmente un organismo.

La Comisión Económica para Europa ha definido el medio ambiente humano como "un conjunto de sistemas compuestos de objetos y condiciones físicas definibles que comprenden particularmente a ecosistemas equilibrados bajo la forma que ya los conocemos o que son susceptibles de adoptar en un futuro previsible y con los que el hombre ha establecido relaciones particulares en cuanto al foco dominante; el proceso dinámico evolutivo, que goza de la misma naturaleza que el medio ambiente humano se encuen. tra fuertemente influido por la interacción e interdependencia entre el hombre y los restantes elementos del medio ambiente sobre el que actúa a los que utiliza, transforma, desarrolla o amolda. Se trata en definitiva, de un proceso en que juegan un papel fundamental las innumerables motivaciones y aspiraciones sociales del hombre".

\section{NOCION JURIDICA DEL AMBIENTE}

Se considera que la primera noción jurídica coherente y orgánica del ambiente se debe a Massimo S. Giannini,quien señaló inicialmente que la acepción del ambiente en el área jurídica es distinta, según tres vertientes que tienen en cuenta su evolución histórica y la situación actual de la normatividad; la primera,con la referencia a la normatividad y movimiento de ideas relativas al paisaje que ve de modo prevalente el aspecto de los bienes ambientales, paisajísticos como bienes públicos objeto de conservación; la segunda, persigue la defensa de los recursos naturales (suelo, aire, 
agua, etc.). contra los actos que constituyen agresión al ambiente de la mutua agresión entre el hombre y la naturaleza, y en la tercera el ambiente es objeto de la planificación territorial. Posteriormente Giannini ofrece una concepción distinta del ambiente como el "ámbito físico de diversas acciones humanas en el cual subsisten sistemas de equilibrio que puede ser modificado pero sólo a costa de reconstituir otros sistemas". Este concepto reduce a dos las estrategias jurídicas: la gestión de los elementos del ambiente y la del territorio. Empero, el ambiente debe ser contemplado en su globalidad, pues la naturaleza se afirma como unidad en la que todos los sectores están íntimamente relacionados entre sí. Esta interrelación no se limita al medio físico. Los antiguos criterios que escindían la naturaleza y la cultura han sido superados pues ambas están intimamente interpenetradas. Esta síntesis se da en el hombre que forma parte de la naturaleza y a la vez la modifica; es criatura y creador de nuevas formas de vida.

El proyecto de Código del Medio Ambiente y los Recursos Naturales define el ambiente como el "sistema de elementos naturales y artificiales de actividades humanas donde interviene el hombre en busca de bienestar natural y espiritual". Esta definición es manifiestamente defectuosa.

Nuestra Constitución menciona varios planos del ambiente (salud, equilibrio ecológico, desarrollo de vida, paisaje) que tienen incidencias en diversos sectores del orden jurídico por lo que debe entenderse que toma el vocablo en sus significación más amplia y que su reglamentación requiere una disciplina unitaria.

El enunciadó del artículo $123^{\circ}$ contiene una trascendental innovación, que consiste en la "Democratización" de la naturaleza, al ponerla a disposición de "todos", eligiendo el ambiente no sólo como patrimonio común, sino propiamente como "patrimonio de la humanidad" es decir que no solo pertenece a las generaciones actuales sino también a las futuras.

El "Derecho a la naturaleza" resulta así uno de los derechos fundamentales del hombre. Podria decirse que nuestra Constitución recoge el pensamiento de Saint Marc cuando dice "Democratizar la naturaleza es también considerarla como un bien público, 
negarse a dejar, 'como pasa hoy, que se apropien, cierren o prohíban los bosques, ríos, mares y montañas es querer que todos pueden tener su parte de hierba verde de la belleza de los paisajes del océano".

"La naturaleza no es el Estado" - señala acertadamente Otto Morales Benites - "es de todos nosotros. Nos pertenece. Debemos defenderla". Es pues impostergable despertar el sentido de propiedad colectiva y educar al pueblo en su uso y disfrute solidario.

Entre los Derechos fundamentales de la persona consagrados en el Título I de la Constitución vigente no figura el derecho "al" ambiente. Ello se debe sin duda a que resulta difícil establecer con precisión el conjunto de facultades constitutivas del mismo y porque la noción de ambiente es simplemente descriptiva pues todos los hombres desarrollan nuestra existencia inmersos en ambientes determinados. Lo que es más, grandes sectores de la población viven en ambientes degradados que no pueden ser considerados como situaciones objeto de protección jurídica sino todo lo contrario. Por consiguiente, se hace necesario calificar al ambiente de "saludable" o "ecológicamente equilibrado" o "adecuado para el desarrollo de la vida" como lo hace nuestra Constitución. Debe entenderse que esta última expresión alude no sólo a la idea puramente cuantitativa del bienestar sino que postula un desarrollo cualitativo y equilibrado de la persona humana en armonía con la naturaleza.

Existe indudable concordancia del artículo $123^{\circ}$ con otros preceptos constitucionales como el derecho a la vida, la integridad física, y al libre desenvolvimiento de la personalidad (artículo $2^{\circ}$ inc. 1), amenazados por los casos de grave contaminación ambiental; con el derecho a la seguridad social (art. $12^{\circ}$ ); con el derecho a la protección de la salud integral (art. $15^{\circ}$ ), con el derecho de la familia a contar con una vivienda decorosa (art. $10^{\circ}$ ); con la tutela del patrimonio cultural de la Nación (art. $36^{\circ}$ ); con las medidas para asegurar la salud e integridad física y mental de los trabajadores (art. $47^{\circ}$ ), con la regulación del uso del suelo urbano de acuerdo al bien común (art. $18^{\circ}$ ); con la evaluación y preservación de los recursos naturales, el fomento de su racional aprovechamiento y la promoción de su industrialización para impulsar el desarrollo 
económico (art. $119^{\circ}$ ) con la obligación de usar la propiedad en armonía con el interés social (art. $124^{\circ}$ ).

\section{LA DECLARACION DE ESTOCOLMO}

La Conferencia de las Naciones Unidas sobre el Medio Humano celebrada en Estocolmo del 5 al 16 de junio de 1972 , pese a las diferencias y enfrentamientos entre los países desarrollados y tercermundistas y haber merecido numerosas críticas, significó el inicio de la "universalización" de los problemas ambientales, pues acordó la elaboración del Plan de las Naciones Unidas sobre el Medio Ambiente (PNUMA) y emitió la Declaración sobre el Ambiente que contiene una Proclamación de 7 Puntos y 26 Principios. En las primeras se expresa que: "La Defensa y el mejoramiento del medio humano para las generaciones presentes y futuras se ha convertido en una meta imperiosa de la humanidad que ha de perseguir al mismo tiempo que las metas fundamentales ya establecidas de la paz y el desarrollo económico y social en todo el mundo, y de conformidad con ellos. El Principio Uno expresa la convicción de que el hombre tiene el derecho fundamental a la libertad, igualdad y al disfrute de las condiciones de vida adecuadas en un medio de calidad tal que le permita llevar una vida digna y gozar de bienestar, y tiene la solemne obligación de proteger y mejorar el medio para las generaciones presentes y futuras".

Proclama también que ambos aspectos del ambiente humano, el natural y el artificial son esenciales para el bienestar y el disfrute de los derechos humanos básicos incluyendo el propio derecho a la vida. En Estocolmo el concepto de ambiente nació de una orientación que se apoyaba en la ciencias naturales, de carácter tecnocrático y preocupada fundamentalmente por las consecuencias materiales y que se transforman en otra más profunda que ha integrado los factores socio-económicos, que en última instancia son la causa de muchos problemas ambientales.

\section{AMBIENTE SALUDABLE}

El primer plano ambiental que distingue el artículo $123^{\circ}$ es el relativo al ambiente "saludable". Este ha sido definido como el complejo de condiciones indispensables a la integridad de la salud hu- 
mana (N.IRTI). La salubridad del ambiente aporta sobre nuevas bases la temática de la tutela de la salud donde ésta misma es individualizada como bien no sólo individual sino social.

La Constitución reconoce el derecho a la salud de la persona como un derecho fundamental al que concede la más amplia protección (art. 16).

Empero, el derecho a la salud en su relación con el ambiente amplía su contenido además de la salvaguardia de la integridad, la garantía de condiciones que garanticen el desarrollo de la existencia del individuo según fundamentales cánones de salubridad.

\section{EQUILIBRIO ECOLOGICO}

El siguiente aspecto ambiental que menciona el art. $123^{\circ}$ es el derecho de habitar en un ambiente ecológicamente "equilibrado".

La biósfera es la capa de la tierra que permite la vida. La biósfera está constituida por parte de la atmósfera (el aire) donde lo viviente se extiende a varios kilómetros, la hidrósfera (aguas marítimas, lacustres y fluviales) en que llega a todas las profundidades y la titósfera (suelo y subsuelo) en cuyo interior sólo alcanza unos metros; el avance científico y tecnológico ha permitido que el hombre ejerza un reflujo global entre los recursos, estructura y composición de la biósfera.

Las partes de la biosfera se encuentran vinculadas por complicados ciclos biogeoquímicos de migración de substancias y energías. (B. Lankorin). También suele denominarse biosfera a "todo el conjunto de organismos que viven en nuestro planeta". (M. Trenzado).

Este sistema natural es anterior al hombre y al sistema socioeconómico y está formado por una parte viva (biótica) compuesta por los microbios, vegetales y animales y otra no viva que le sirve de sustento (abiótica) formada por los elementos naturales (agua, oxígeno, anhidrido carbónico, etc.) materia orgánica, subproductos y otros factores físicos (radiación solar, clima, vientos, etc.) 
universo en este sistema que es biosfera. El hombre vive y es parte del mismo y constituye en última instancia su habitat natural.

A mediados del siglo pasado la idea puramente descriptiva de la naturaleza que mantenían los riesgos científicos adquirió singular dinamismo como consecuencia de la concepción evolucionista de las especies elaborada por Darwin que planteó las bases de la ecología como ciencia sobre las relaciones de los seres vivos con su habitat. El biólogos Ernest Haekel fue el primero en emplear la palabra Ecología (1866) definiéndola como "el conjunto de conocimientos referentes a la economía de la naturaleza, la investigación de todas las relaciones del animal tanto en su medio inorgánico como orgánico".

La ecología ha evolucionado desde su concepto inicial exclusivamente biológico que se mantiene hasta ahora distinguiendo dos ramas: la autoecología que estudia las relaciones entre los seres vivos y los ecosistemas y las relaciones de éstos con el medio ambiente, cuyos orígenes se encuentran en los trabajos de A. Von Humboldt sobre las relaciones del clima con los tipos de vegetación y de A. Voelkov que fue el primero en haber planteado el problema de las transformación activa de la naturaleza bajo la acción humana.

Los aportes de K. Marx y F. Engels desde el ángulo del carácter dialéctico de la interacción del sistema hombre-sociedad-naturaleza y otros científicos como E.P. Odum han ampliado el campo de la ecología como ciencia de síntesis multidisciplinaria e interdisciplinaria.

Con la Revolución Científico Tecnológica del siglo XX la Ecología ha avanzado a una situación prominente favorecidos por el perfeccionamiento y por la aplicación de conceptos y técnicas de otras ciencias especialmente de la Química y la Física y se presenta como instrumento de la mayor importancia para todas las naciones porque su enfoque abarca toda la problemática de equilibrio entre el hombre y sus relaciones y el medio y sus posibilidades.

El objeto de la Ecología queda claramente delimitada si la 
consideramos con el concepto de los sistemas cuya complejidad abarca desde el nivel molecular hasta los ecosistemas.

El "ecosistema" es definido como un ambiente más o menos delimitado donde los recursos locales son reciclados por una biomasa de plantas y de animales asociados en procesos compatibles (Pierre Danserau).

Evidentemente el proceso central del ecosistema es la alimentación de la cual depende la propia mantención de la vida de éste. De ahí la importancia del estudio de los vínculos tróficos de los sistemas.

Se ha señalado que entre las actividades que preocupan actualmente al mundo técnico-científico ninguna tiene consecuencias tan profundas para el futuro de la humanidad como la conservación del ambiente natural deì hombre lo que confiere a la Ecología una visión global que comprende asuntos de salud pública, alimentación e ingeniería que abarcan prácticamente todas las ciencias Físicas y Sociales.

La ocupación de la tierra y la explotación de los recursos naturales no debe estar liberada a la "libre iniciativa privada guiada por el afán de lucro que conduce a su depredación por cuanto no tiene en cuenta ciertos principios ecológicos dirigidos a preservar los recursos ambientales para usufructo de las futuras generaciones".

Como advierte W. Duarte de Barros debe buscarse la "Seguridad del desarrolio". Ello importa la afirmación de la búsqueda de una garantía de continuidad del proceso de desarrollo no sólo para algunas generaciones, sino permanente que mantenga la composición esencial de la propia Nación.

Actualmente se postula que la ecología es una disciplina bidimensional cuyo objeto es, de un lado, el ambiente físico que constituye el soporte de la vida y de otro, por los ecosistemas o relaciones y procesos dinámicos de interacción entre el medio físico y los organismos vivos a los que sirve de soporte. 
Con relación a las ciencias sociales se ha desarrollado la rama de la ecología humana que analiza los procesos a través de los cuales el hombre puede modificar el equilibrio de los ecosistemas con las consiguientes repercuciones para el ambiente y el desarrollo de la vida humana.

El concepto de ecosistema es un aporte fundamental de la ecología que ha establecido que las especies no viven aisladas sino con otras en estricta interdependencia entre sí y con el ambiente en situación de equilibrio dinámico cuya ruptura produce la extinción del sistema.

\section{DERECHO ECOLOGICO O DERECHO AMBIENTAL}

El desarrollo de la Ecología significó la comprensión de que el ambiente constituye una globalidad, un todo cuyos diversos elementos interaccionan entre si en equilibrio dinámico. Esta verdad recién percibida en la segunda mitad del presente siglo determinó la necesidad y creación de nuevas técnicas y normas legales para el manejo integrado de los recursos, que han dado origen a una nueva rama del Derecho.

Con respecto a la denominación de esta nueva disciplina jurídica no hay acuerdo entre los especialistas si debe llamarse Derecho Ecológico o Derecho Ambiental. Sergio Ferraz denomina "derecho ecológico al conjunto de técnicas, reglas e instrumentos jurídicos orgánicamente estructurados para asegurar un comportamiento que no atente contra la sanidad del medio ambiente". Por su parte Diego de Figaereido Moreira define al Derecho Ecológico como compuesto de "técnicas, reglas e instrumentos jurídicos sistematizados e informados por principios aprobados que tengan por fin la disciplina del comportamiento relacionado con el medio ambiente".

En cambio, Martín Mateo, J. Cano y P.A. Leme Modrado, se inclinan por la denominación de Derecho Ambiental señalando que las definiciones anteriores se refieren al ambiente.

Entre nosotros, los estudios jurídicos sobre la materia se encuentran en una fase inicial. De la terminología constitucional pa- 
rece derivarse la conveniencia de la denominación Derecho Ambiental. Empero, Audaluz y Valdez se inclinan por la denominación Derecho Ecológico "como ciencia normativa que se pone al servicio de la conservación" y como "una simple preferencia y no como un imperativo científico" en lo que coincidimos.

El Derecho Ambiental, en su acepción más amplia, busca reorientar las relaciones existentes entre el hombre y su medio. $\mathrm{Su}$ objeto es lograr que la actividad humana opere racionalmente sobre la naturaleza en función de una realidad perfectamente establecida (por la ciencia) que dé cuenta de las limitaciones que la acción humana sobre los recursos naturales y el ambiente que le son necesarios. Esto tiene un sentido muy claro: proteger al hombre de sus propias obras y preservar la integridad de los ecosistemas naturales que garantizan la vida sobre el planeta.

Con mayor precisión puede decirse que el Derecho Ambiental regula las actividades productivas en general cuando se relacionan con los recursos naturales, en función de su utilización explotación $o$ aprovechamiento racional, que significa el mantenimiento sostenido de estos para su aprovechamiento continuado -en el caso de los renovables-; y su reutilización o reciclaje- en el caso de los no renovables.

Desde hace tiempo las Naciones Unidas han reconocido que el desarrollo implica la redistribución de los ingresos y recursos productivos. A partir de los años 70 han advertido la necesidad de la defensa del medio ambiente y ha señalado la necesidad de una redifinición del concepto de planificación del desarrollo en la que el uso sostenido de los recursos naturales y predición del ambiente es tarea fundamental. De ahí que la forma del desarrollo ha pasado a ser la siguiente: mayor producción, más distribución, más preservación del medio ambiente. Es lo que algunos especialistas denominan eco-desarrollo.

En realidad, se trata del surgimiento de una nueva civilización basada en la armonía de los bienes materiales y los inmateriales, distinta de la civilización capitalista depredadora de la naturaleza en su afán de ganancia ilimitada y sembradora de muerte. 
No puede pues causarnos extrañeza que la Ecología llamada "la primera piedra de la humanidad futura" haya conmocionado el Derecho Agrario penetrándolo desde su propio núcleo como una “cuarta dimensión".

De ahí que algunos autores hayan planteado la alternativa de considerar al derecho agrario como parte de un Derecho de la Naturaleza denominado por la preocupación ecológica y forjado a medida de ésta y que podría llamarse Derecho Ambiental.

La unidad e interdependencia de los recursos naturales renovables (suelos, agua, flora y fauna) como integrantes de un univerșo biológico productor de materia orgánica ha llevado a Ramón Vicente Casanova a concebir el Derecho Agrario como "Derecho de los recursos naturales renovables que intenta ordenar las relaciones jurídicas que se originan en la tenencia y aprovechamiento de los recursos naturales renovables, concebid os como unidad en la figura de la propiedad territorial (del Estado o de los particulares, individual o colectiva), con miras a establecer una conveniencia humana que sea al mismo tiempo convivencia con la naturaleza".

\section{EL AMBIENTE EN EL DERECHO CONSTITUCIONAL COMPARADO}

Puede decirse, que la recepción del tema del ambiente en los textos constitucionales es de data reciente y se ha producido con más amplitud a medida que se ha ido tomando conciencia de su importancia prioritaria.

La Primera Constitución que se refiere al Ambiente es la Carta Fundamental de la República de Italia promulgada el 21 de diciembre de 1947 que en su articulo $9^{\circ}$ establece que:

"La República salvaguardará el paisaje y el patrimonio histórico y artístico de la Nación". El desarrollo hermenéutico de esta norma en apariencia concebida sólo para la conservación de las bellezas naturales ha abarcado toda la problemática del ambiente.

El artículo 24 Septies añadido por votación popular de 6 de 
junio de 1971 a la Constitución Federal de la Confederación Suiza establece que:

"La confederación legislará sobre la protección del hombre y de su ambiente natural contra las interferencias nocivas o molestas que se le inflijan y combatirá, en especial, la contaminación del aire y el ruido".

El artículo 25 señala que:

"La Confederación tendrá la facultad de dictar disposiciones legislativas para regular el ejercicio de la pesca y de la caza con vistas especialmente a la conservación de la caza mayor en las montañas y a la protección de las aves útiles a la agricultura y la silvicultura".

La Constitución de Bulgaria promulgada el 18 de mayo de 1971 establece en su artículo 30 que:

"La tierra como riqueza natural y medio básico de jurisdicción será protegida y utilizada del modo más racional en interés de la sociedad". Asimismo prescribe en el art. 31 que:

"Constituyen una obligación para los órganos del Estado, las empresas cooperativas, y las organizaciones sociales y un deber para todo ciudadano la protección y la salvaguardia de la naturaleza y de las riquezas naturales, de las aguas, del aire y del suelo, así como de los movimientos de la cultura".

Por su parte la Constitución de la República Democrática Alemana de 7 de octubre de 1974 en términos semejantes establece que:

"El Estado y la sociedad velarán en interés del bienestar del pueblo, por la protección de la naturaleza. Deberán ser garantizados por los órganos competentes y serán además tarea de todo ciudadano la limpieza de las aguas y del aire así como la protección de la flora y de la fauna y de las bellezas paisajistas de la patria" (artículo $15^{\circ}$ párrafo $2^{\circ}$ ). 
La Constitución de Grecia, vigente a partir del 11 de junio de 1975 , dedica al artículo 24 a una precisa regulación de los problemas ambientales estableciendo lo siguiente:

1.- Constituye obligación del Estado la protección del ambiente natural y cultura. El Estado estará obligado a adoptar medidas especiales preventivas o represivas con vistas a la conservación del aquél.

La ley regulará las modalidades de protección de los bosques y de los espacios forestales en general...".

2.-Quedan bajo la regulación y control del Estado la ordenación del territorio, la formación, el desarrollo, el urbanismo y la extensión de las ciudades y de las regiones urbanizables en general con el objeto de garantizar la funcionalidad y el desarrollo de las aglomeraciones y las mejores condiciones de vida posible".

6.- Quedan bajo la protección del Estado los monumentos, así como los lugares históricos y sus elementos. . .

Puede advertirse que la Carta Fundamental Griega contiene una concepción integral del ambiente en sus tres aspectos físicobiológico, urbanístico y cultural".

La Constitución de la República Socialista Federativa de Yugoeslavia promulgada el 21 de febrero de 1974, dedica a la preservación y mejora de las condiciones ambientales el artículo $87^{\circ}$ que establece:

"Los trabajadores y los ciudadanos, las organizaciones de Trabajo Asociado, las Comunidades Sociopolíticas, las Comunidades Laborales y otras organizaciones y Comunidades Autogestionadas tendrán el derecho y el deber de asegurar las condiciones para preservar y desarrollar los valores del medio ambiente humano creados por la naturaleza y el trabajo, así como de preservar y eliminar los efectos dañinos que por la contaminación del aire, el suelo, las aguas, las corrientes y el mar, por ruidos o de otro modo, pongan en peligro estos valores y amenacen la vida y la salud de los hombres"'. 
La Constitución de la República Portuguesa, proclamada el 2 de abril de 1976, es una de las más avanzadas en la materia. En los artículos $64^{\circ}, 65^{\circ}$ y $66^{\circ}$ ubicados en el Capítulo Tercero "De los Derechos y Deberes Sociales" del Título III sobre "los Derechos y Deberes Económicos, Sociales, Culturales, y brinda una amplia tutela a la salud, la vivienda, el ambiente y la calidad de vida, declarando que:

1.- Todos tienen derecho a un ambiente de vida humano, sano y ecológicamente equilibrado y el deber de defenderlo.

2.- Corresponde al Estado mediante sus propios organismos y la apelación de iniciativas populares:

a) Prevenir y controlar la contaminación y sus efectos y las formas perjudiciales de erosión;

b) Ordenar el espacio territorial de modo que resulten paisajes biológicamente equilibrados;

c) Crear y desarrollar reservas y parques naturales y de recreo, así como clasificar y proteger paisajes y lugares de tal modo que se garantice la conservación de la naturaleza y la preservación de valores culturales de interés histórico o artístico;

d) Promover el aprovechamiento racional de los recursos naturales, salvaguardando su capacidad de renovación y la estabilidad ecológica.

3.- Todo ciudadano perjudicado o amenazado en el derecho que se refiere el acápite, podrá pedir con arreglo a lo previsto en la ley, la cesación de las causas de violación del mismo y la correspondiente indemnización.

4.- El Estado debe promover la mejora progresiva y acelerada de la calidad de vida de todos los portugueses.

La Constitución de la República Socialista de Albania, de 29 de diciembre de 1976 , establece que:

"Constituye un deber del Estado, de las organizaciones económicas y sociales $y$ de todos los ciudadanos la protección de la 
tierra, de las riquezas naturales, de las aguas contra cuales quiera daños y contra la contaminación".

Otro modelo importante es la nueva Constitución Soviética, de 7 de octubre de 1977 , cuyo artículo $18^{\circ}$ ha sido calificado por el maestro italiano Antonio Carrozza como "un decálogo de los principios fundamentales referentes a la tutela de la naturaleza, no considerada únicamente como tierra cultivable". Dicho enunciado dice:

"En interés de las generaciones presentes y futuras, la Unión Soviética adopta los procedimientos necesarios para la tutela y el uso racional y científicamente fundado, de la tierra, del subsuelo, de los recursos hidricos, de la flora y de la fauna, para la conservación de la pureza de la atmósfera y del agua, para la garantía de la reproducción de las riquezas naturales y para el mejoramiento del ambiente que mejora al hombre".

La Constitución Española, de 31 de octubre de 1978 proclama el derecho al ambiente y vincula la explotación racional de los recursos naturales con la mejora de la calidad de vida y la defensa y restauración del ambiente. Su artículo $45^{\circ}$ establece:

1.- Todos tienen derecho a disfrutar de un medio ambiente adecuado para el desarrollo de la persona, así como el deber de conservarlo.

2.- Los poderes públicos velarán por la utilización racional de todos los recursos naturales, con el fin de proteger y mejorar la calidad de vida y defender y restaurar el medio ambiente, apoyándose en la indispensable solidaridad colectiva".

Puede advertirse que la mayoria de las Constituciones que hablan específicamente de la protección del ambiente pertenecen al bloque de las llamadas "democracias populares" y que obedecen a reformas constitucionales efectuadas después de 1968 considerado como "fecha crucial" de afirmación del ecologismo. En cambio son minoría las Constituciones de las democracias occidentales que aluden esta materia y también son posteriores a dicha fecha. 
En los distantes países en que no se han operado reformas Constitucionales recientes por lo que no existe en sus Cartas Fundamentales una expresa referencia al ambiente se ha desarrollado una amplia legislación sobre la materia como Francia, Alemania Federal, Estados Unidos de Norte América y en Iberoamérica, Brasil, Colombia y Venezuela.

Los textos Constitucionales ubican la regulación ambiental dentro del título referente a la Política Económica y Social, es decir entre de la llamada "Constitución Económica".

Puede advertirse que si bien todas las Constituciones mencionadas se refieren al ambiente físico o entorno material sólo las más recientes mencionan el ambiente cultural y solamente la de Grecia se refiere expresamente a lo urbanístico.

\section{PRESERVACION DEL PAISAJE Y LA NATURALEZA}

El tercer Aspecto del Ambiente que contempla el primer acápite del artículo $123^{\circ}$ de la Constitución Política es el derecho de toda persona a la preservación del Paisaje y la Naturaleza. La redacción del dispositivo resulta notablemente defectuosa por cuanto la "preservación" de algo no puede constituir un derecho.

La Constitución de 1933 no hacía mención al paisaje. El paisaje no es un "telón de fondo" sino algo dinámico que experimenta rápidas modificaciones.

Una amplia corriente de la Ecología actual ha puesto de relieve los aspectos emocionales y estéticos de la percepción del paisaje naturales que se reflejan en la imaginación y el pensamiento del hombre, lo que hace necesario la valoración del paisaje y su tutela jurídica.

Después de la primera Guerra Mundial connotados geógrafos sostenian que en el paisaje convergen la naturaleza y la acción humana, y que "los paisajes naturales son los culturales, pues no se puede prescindir de la historia" ( $O$. Schlutter).

El paisaje al principio fue considerado únicamente "como be- 
lleza natural de especial mérito estético" lo que determinaba, según A. Pérez Luño, que las medidas protectoras tuvieran una significación:

a) Fragmentaria, porque no anuncian globalmente la defensa de la naturaleza, sino de algunas de sus manifestaciones caracterizados por su valor pictórico;

b) Estática, porque la naturaleza se contempla como un cuadro inmóvil cuya tutela se agota en medidas que aseguran su persistencia;

c) Negativa, ya que se trataba de evitar modificaciones en determinados sectores del medio natural prescindiendo de aquellas alternativas que pueden contribuir a potenciar su significación;

d) Abstracta, porque soslayaba la necesaria interacción entre el paisaje y los hombres, descuidando el papel de la naturaleza como dimensión refleja del hombre en la que ésta proyecta sus realizaciones y exigencias.

Actualmente el concepto de "paisaje" y "naturaleza" no se limita a la belleza "panorámica" sino que implica otros valores: naturales, geológicos, de la fauna y la flora, históricos. "Se trata de un valor complejo inserto en el concepto general de territorio". (D. Magdalena).

De acuerdo a las exigencias de la sociedad actual la tutela jurídica del paisaje y la naturaleza está cargada de significado que va de los valores estéticos a los naturales en sentido propio, a los históricos y a todos aquellos más propiamente humanos.

Entre las instituciones relativas a la preservación del paisaje y la naturaleza se encuentran:

a) El vinculo paisajistico, que consiste en adoptar las providencias cautelares que consisten en la prohibición o suspensión de labores en bienes calificables como bellezas naturales.

b) Los parques son zonas delimitadas que se caracterizan por la presencia de formaciones geológicas o paleontológicas, flora y fauna, valores paisajísticos y a menudo, aunque no necesariamente, de valores históricos-ambientales.

c) Las reservas naturales son extensiones territoriales más reduci- 
das que los parques dotadas de una particular caracterización de la finalidad conservativa del ambiente natural prevalentemente concentrada en los valores botánicos, forestales, faunísticos, sin limitación, de acuerdo a fines propiamente culturales y científicos con exclusión de su apertura a un disfrute generalizado de la colectividad. (A. Ferri).

La última parte del artículo $123^{\circ}$ de la Constitución establece que: "todos tenemos el deber de conservar dicho ambiente" (saludable, ecológicamente equilibrado y adecuado para el desarrollo de la vida). La conservación, es pues, positiva, no se reduce a una simple abstención o "no hacer" sino el mantenimiento, la utilización racional, la reestructuración y la mejora del ambiente. Con mayor razón no son permisibles los aspectos humanos de deterioro ambiental como la contaminación, la desertificación, la depredación.

\section{LA CONTAMINACION AMBIENTAL}

El segundo acápite del artículo $123^{\circ}$ señala que: "Es obligación del Estado, prevenir y controlar la contaminación ambiental". La contaminación es una forma cualitativa de degradación ambiental. La contaminación suele delimitarse según el elemento afectado (aire, agua, suelo).

Durán Dantes distingue dos tipos históricos de contaminación atmosférica:

1) La contaminación clásica de las grandes aglomeraciones industriales debida fundamentalmente a las de industrias químicometalúrgicas y a la combustión del carbón. Un caso notorio fue el de los humos de La Oroya provocado por la función de la Compañia Minera Cerro de Pasco que contaminó las de los departamentos de Pasco, Lima y Junín.

2) La contaminación moderna que corresponde a la etapa de los hidrocarburos. Su control es uno de los problemas más graves de nuestros tiempos.

La contaminación ambiental ha sido definida como "la alteración desfavorable de nuestro entorno como subproducto total o 
parcial de las actividades humanas y a través de los efectos directos o indirectos que se derivan de los cambios de la distribución de la energía, los niveles de radiación, la constitución química y física y la abundancia de los organismos". Estos cambios pueden afectar al hombre directamente o a través del abastecimiento de agua y de los productos agrícolas o biológicos, de sus objetos o bienes materiales o de sus posibilidades de disfrute de la naturaleza".

Otra definición generalizada de contaminación se refiere a "cambios no deseables en las características físico-químicas y biológicas del aire, la tierra y el agua, que puedan afectar nocivamente la vida humana o la de otras especies valiosas, los procesos industriales, las condiciones de vida y la sociedad en general".

J.E. BAUGH define la contaminación como "la descarga de substancias extrañas en el ambiente en cantidades tales que perjudiquen la propiedad, la vida y/o salud del hombre o la integridad de los ecosistemas naturales.

Los tres grandes elementos que constituyen la biósfera y cuyas características físico-químicas y bacteriológicas los diferencia entre sí, son precisamente el aire, el agua y los suelos. Cada uno de ellos se ve afectado de manera especial por la actividad humana, principalmente industrial, pero el efecto muchas veces se traslada de uno a otro. Esta clasificación tripartita sirve como pauta en el análisis ecológico y en las investigaciones sobre conservación y descontaminación ambiental. También el Derecho tradicional toma en cuenta esta clasificación del ecosistema mundial, aunque tiende a equivocarse al no llegar a regular integralmente los tres ecosistemas, descuidando, por ejemplo, el de la atmósfera y perjudicando así el logro de los objetivos trazados, y la eficiencia de sus normas de control. 